\title{
Forecasting LABOUR ProduCtivity GROWTH IN NORWAY FOR THE PERIOD 2012-2021 USING ARIMA MODELS
}

\author{
PIRooz SAMAVATI*
}

\section{INTRODUCTION}

Labour productivity is a relationship between production and the factors of production (Freeman, 2008). Basically, labour productivity is equal to the ratio between a volume measure of output (gross domestic product (GDP) or gross value added) and a measure of input use (total number of hours worked or total employment) (Freeman, 2008).

More specifically, labour productivity measures the amount of real GDP produced by an hour of labour. Real GDP grows when aggregate working hours and labour productivity grow, assuming ceteris paribus. ${ }^{1}$

According to the neoclassical models of growth (such as the Solow model), labour productivity growth is mainly explained by progress in science and technology (Kaldor, 1966). This fact helps us to better understand Verdoorn's law. Verdoorn's law states that there is a linear relationship between growth in output and growth in productivity in the long run (Verdoorn, 1949; Kaldor, 1966). This relationship can be explained by the theory of cumulative causation. According to this theory, it is primarily growth in effective demand that stimulates technological growth through increasing division of labour potential and through learning-by-doing. The resulting labour productivity increase stimulates higher outputs through the extension of existing markets and the opening up of new markets. This suggests that labour productivity gains and growth in output comprise a mutually reinforcing mechanism (Kaldor, 1966; Schmookler, 1966; McCombie, 2003; Van Geenhuizen, 2009). ${ }^{2}$

DOI: $10.2478 /$ wrlae-2013-0048

* $\mathrm{PhD}$ student working under the supervision of Prof. Jaroslaw Kundera at the Economics Institute, Faculty of Law, Administration and Economics, Wroclaw University; pirooz_samavati@yahoo.com

${ }^{1}$ R Freeman, 'Labour Productivity Indicators' (2008) OECD Statistics Directorate, Division of Structural Economic Statistics, 5-15 < http://www.oecd.org/std/labour-stats/41354425.pdf > accessed 18 November 2013.

${ }^{2} \mathrm{~N}$ Kaldor, Causes of the Slow Growth in the United Kingdom (Cambridge: Cambridge University Press 1966) 289; J Schmookler, Invention and economic growth (Harvard University 
To a great extent Norway managed to mitigate the global stagflation of the 1970s resulting from the global oil crisis through utilizing revenues from oil exports. Consequently, Norway had higher economic growth and a lower unemployment rate compared to most of the other Western countries suffering from the 1970s crisis. However, since Norwegian firms failed to adapt to markets, Norwegian labour productivity lagged behind the changes in international markets. This phenomenon, alongside huge growth in oil revenue (from 1973 to the end of 1985), made a significant contribution to the deindustrialization of Norway (Grytten, 2008). Thus, compared to the 1948-1970 period, labour productivity growth in Norway was generally low and variable from the mid1970s until the late 1980s (Hagelund, 2009). Figure 1 displays the changes in annual labour productivity growth in Norway over the last three decades (19712011). As figure 1 suggests, it does not appear that the mean level of labour productivity growth in the 1990s was higher than the mean rate of growth in the 1970s and 1980s (although possibly the variance of the growth in the 1990s was lower). Moreover, the level of growth in the 2000s is not greater than the mean level of growth in the 1990s: it only seems to be greater than the level of growth in the final two years of the 1990s. There seems to be a change (a fall in the growth rate) in the middle of the 2000s, before a slight recovery at the end of the period under consideration (1971-2011). The 2007-2009 financial and economic crisis in Norway, which resulted from the banking crisis, caused an even greater fall in labour productivity growth, culminating in it reaching its lowest point in the previous three decades in $2008 .^{3}$ Indeed, a fall in oil revenue and non-oil sector stagnation resulting from the crisis led to a lower output growth and lower labour productivity growth (Hagelund, 2009). After 2008 labour productivity

Press, Cambridge, Massachussets 1966)181-204

$<$ http://journals.cambridge.org/action/displayAbstract?fromPage $=$ online\&aid=8326359 > accessed 18 November 2013; JP Verdoorn, 'On the Factors Determining the Growth of Labour Productivity' (1949) (in L. Pasinetti (ed.). Italian Economic Papers 59, Vol. II, Oxford: Oxford University Press 1993) 3-10 ; JSL McCombie , M Pugno, B Soro, 'Introduction' (In MP McCombie, B Soro (eds), Productivity Growth and Economic Performance, Palgrave Macmillan, London 2002) 1-27; M Van Geenhuizen, DM Trzmielak, DV Gibson, M Urbaniak, Value-Added Partnering and Innovation in a Changing World (Purdue University Press 2009) 358-362 <http://www.thepress.purdue.edu/titles/format/9781557535139> accessed 18 November 2013; C Kennedy 'Induced bias in innovation and the theory of distribution' (1964) in Economic Journal, Vol. 74, 541-547 <http://www.jstor.org/stable/2228295?origin=JSTORbelow-page $>$ accessed 18 November 2013; S Scarpetta, T Tressel, 'Boosting Productivity via Innovation and Adoption of New Technologies: Any Role for Labour Market Institutions?'(2004) World Bank Policy Research Working Paper, no. 3273 $\leq \mathrm{http} / /$ ideas.repec.org/p/wbk/wbrwps/3273.html> accessed 18 November 2013; R Vergeer, A Kleinknecht, 'Jobs versus Productivity? The causal link from wages to labour productivity growth' (2007) TU Delft, The Netherlands, 2-6 $\leq$ http://www.fep.up.pt/conferencias/eaepe2007/Papers\%20and\%20abstracts_CD/Vergeer.pdf > accessed 18 November 2013.

${ }^{3}$ Similar to Norway, labour productivity growth appeared to fall in some other industrial European Union (EU) and non-EU countries before the 2007-2009 financial and economic crisis took place (Appendix A); Therefore, this phenomenon is not specific to Norway. It seems more general rather than being a consequence of the global financial and economic crisis. 
growth in Norway started to increase. The Norwegian economy also started to recover in 2010 (IMF, 2012). ${ }^{4}$

Limited access to funds and a decrease in investments as a result of the financial and economic crisis could lead to a decline in research funding which, consequently, could slow down technological development and labour productivity growth in the longer term (Hagelund, 2009). Furthermore, based on Verdoorn's law, the reduced output resulting from the economic crisis could cause a decrease in labour productivity growth. From the perspective of the 20072009 financial and economic crisis in Norway, it is interesting to forecast Norwegian labour productivity growth for the coming decade. ${ }^{5}$

Figure 1. Labour productivity growth time series plot in Norway, 19712011

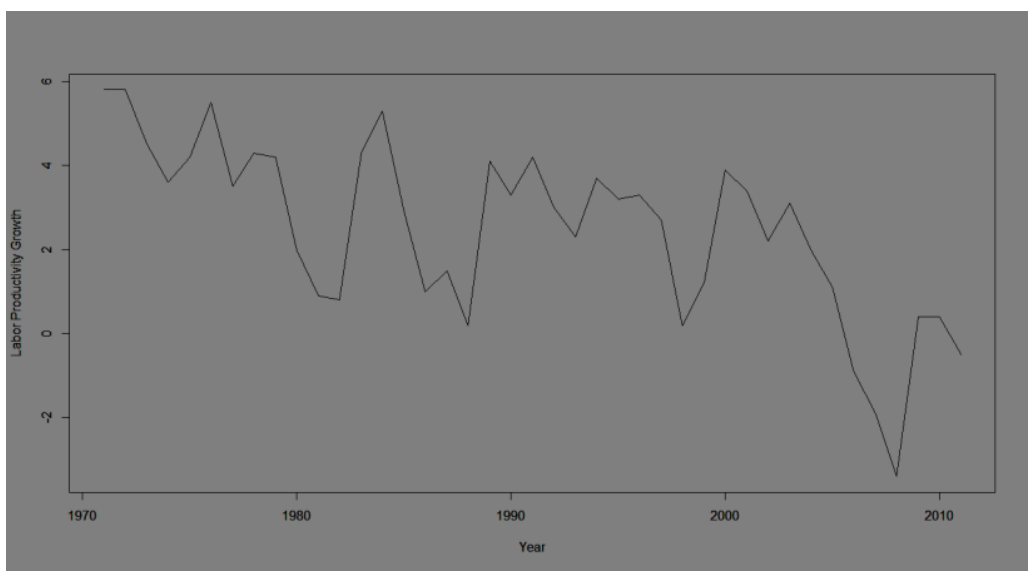

Source: Data is extracted from OECD statistics $<$ http:// stats.oecd.org $>$ accessed 18 November 2013.

Considering the aforementioned facts, this paper focuses on forecasting labour productivity growth in Norway for the period 2012-2021 through an autoregressive integrated moving average (ARIMA) model using its successive values between 1971 and 2011. The Box-Jenkins methodology is applied to select the appropriate ARIMA model. After identifying the model and forecasting Norwegian labour productivity growth, this paper discusses the

\footnotetext{
${ }^{4}$ Ola Grytten, 'The Economic History of Norway' (2008) EH.Net Encyclopedia, edited by Robert Whaples. March 16, $2008<$ http://eh.net/encyclopedia/article/grytten.norway> accessed 18 November 2013; K Hagelund, 'Productivity growth in Norway 1948-2008' (2009) Special adviser, Economics Department, Norges Bank, Economic bulletin 2, 4-15 $<$ http://www.norgesbank.no/Upload/77502/EN/Hele\%20BUL.pdf> accessed 18 November 2013; IMF Executive Board Concludes 2011 Article IV Consultation with Norway, Public Information Notice (PIN) No. 12/9, February 2, $2012<$ http://www.imf.org/external/np/sec/pn/2012/pn1209.htm> accessed 18 November 2013.

${ }^{5}$ Hagelund (n 4).
} 
selected model. Moreover, it briefly interprets the forecast from an economic perspective. The paper is organized as follows. Section 2 introduces ARIMA models. Section 3 presents the Box-Jenkins methodology. In section 4, the model and the results are obtained. Section 5 discusses the model and the results and presents a conclusion.

\section{ARIMA MODELS}

Since labour productivity growth data has a time-series nature, in order to model it as a function of its past values a pattern is identified with the assumption that this pattern will persist in the future. In order to identify patterns of the series and forecast future points in it, an autoregressive integrated moving average model (ARIMA) is fitted to the data in this paper.

Before introducing ARIMA models, it is necessary to briefly present its two constituents, namely autoregressive models and moving average models (Hyndman and Athanasopoulos, 2012). In an autoregressive model, the variable of interest is forecasted using a linear combination of past values of the variable. Thus, an autoregressive model of order $\mathrm{p}$ can be written as: $\mathrm{y}_{\mathrm{t}}=\mathrm{c}+\varphi_{1} \mathrm{y}_{\mathrm{t}-1}+\varphi_{2} \mathrm{y}_{\mathrm{t}}$ ${ }_{2}+\ldots \ldots+\varphi_{p} y_{t-p}+e_{t}$, where $e_{t}$ is white noise. ${ }^{6}$ This is similar to a multiple regression but lagged values of $\mathrm{y}_{\mathrm{t}}$ is considered as predictors and $\mathrm{c}$ is considered as an intercept. An autoregressive model is referred to as an AR (P) model. For an AR (1) model, $y_{t}$ is equivalent to White Noise (WN) when $\varphi_{1}=0$. $y_{t}$ is equivalent to a Random Walk (RW) without drift when $\varphi_{1}=1$ and $\mathrm{c}=0 . \mathrm{y}_{\mathrm{t}}$ is equivalent to a Random Walk (RW) with drift when $\varphi_{1}=1$ and $\mathrm{c} 0$. When $\varphi_{1} 0$ and $\mathrm{c}=0, \mathrm{y}_{\mathrm{t}}$ tends to fluctuate between positive and negative values. Autoregressive models basically apply to stationary data. This being the case, it is necessary to impose some constraints on the values of the parameters. For instance, for an AR (1) model: $-1<\varphi_{1}<1$ and for an AR (2) model: $-1<\varphi_{2}<1, \varphi_{1}+$ $\varphi_{2}<1, \varphi_{2}-\varphi_{1}<1$ (Hyndman and Athanasopoulos, 2012).

A moving average model is the second constituent of ARIMA models. A moving average model uses past forecast errors in a regression-like model instead of using past values of the forecast variable in a regression. A moving average model of order q can be written as $\mathrm{y}_{\mathrm{t}}=\mathrm{c}+\mathrm{e}_{\mathrm{t}}+\theta_{1} \mathrm{e}_{\mathrm{t}-1}+\theta_{2} \mathrm{e}_{\mathrm{t}-2}+\ldots \ldots+\theta_{\mathrm{q}} \mathrm{e}_{\mathrm{t}-\mathrm{q}}$, where $\mathrm{e}_{\mathrm{t}}$ is the white noise and $\mathrm{c}$ is considered an intercept.

A moving average model is referred as an MA (q) model. It is possible to write any stationary AR (p) model as an MA $(\infty)$ model. $^{7}$ It is important to mention that the reverse result holds if some constraints on the MA parameters are imposed.

\footnotetext{
${ }^{6} \mathrm{~A}$ white noise process has zero mean, constant variance, and it is uncorrelated in time. As its name suggests, white noise has a power spectrum which is uniformly spread across all allowable frequencies.

${ }^{7}$ For example, using repeated substitution, it can be demonstrated for an AR (1) model: $\mathrm{y}_{\mathrm{t}}=\varphi_{1} \mathrm{y}_{\mathrm{t}}$ ${ }_{1}+\mathrm{e}_{\mathrm{t}}=\varphi_{1}\left(\varphi_{1} \mathrm{y}_{\mathrm{t}-2}+\mathrm{e}_{\mathrm{t}-1}\right)+\mathrm{e}_{\mathrm{t}}=\varphi_{1}{ }^{2} \mathrm{y}_{\mathrm{t}-2}+\varphi_{1} \mathrm{e}_{\mathrm{t}-1}+\mathrm{e}_{\mathrm{t}}=\varphi_{1}{ }^{3} \mathrm{y}_{\mathrm{t}-3}+\varphi^{2}{ }_{1} \mathrm{e}_{\mathrm{t}-2}+\varphi_{1} \mathrm{e}_{\mathrm{t}-1}+\mathrm{e}_{\mathrm{t}}$ etc. Provided $-1<\varphi_{1}<1$, the value of $\varphi^{\mathrm{k}} 1$ will get smaller as $\mathrm{k}$ gets larger. Then, eventually, MA $(\infty)$ process is obtained: $\mathrm{y}_{\mathrm{t}}=\mathrm{e}_{\mathrm{t}}+$ $\varphi{ }_{1} \mathrm{e}_{\mathrm{t}-1}+\varphi^{2}{ }_{1} \mathrm{e}_{\mathrm{t}-2}+\varphi^{3}{ }_{1} \mathrm{e}_{\mathrm{t}-3}+\ldots \ldots$.
} 
When any MA (q) process can be written as an AR $(\infty)$ process, the MA model is called "invertible". Invertibility constraints are similar to stationarity constraints. For example, for an MA (1) model: $-1<\theta_{1}<1$ and for a MA (2) model: $-1<\theta_{2}<1$, $\theta_{2}+\theta_{1}>-1, \theta_{1}-\theta_{2}<1$ (Hyndman and Athanasopoulos, 2012).

If an autoregressive model and a moving average model are combined with differencing, a non-seasonal ARIMA model is obtained (Hyndman and Athanasopoulos, 2012). ARIMA is an acronym for Autoregressive Integrated Moving Average model ("integration" in this context is the reverse of differencing).

The ARIMA model can be written as: $\mathrm{t}=\mathrm{c}+\varphi_{1 \mathrm{t}-1}+\ldots \ldots+\varphi_{\mathrm{pt}-\mathrm{p}}+\theta_{1} \mathrm{e}_{\mathrm{t}-1}+\ldots \ldots+$ $\theta_{\mathrm{q}} \mathrm{e}_{\mathrm{t}-\mathrm{q}}+\mathrm{e}_{\mathrm{t}}(1)$, where ${ }_{\mathrm{t}}$ is the differenced series (it may have been differenced more than once), $e_{t}$ is the white noise and $c$ is considered an intercept . The predictors on the right hand side include both lagged values of $y_{t}$ and lagged errors. This is called an ARIMA (p, d, q) model, where

$\mathrm{p}=$ an order of the autoregressive part

$\mathrm{d}=\mathrm{a}$ degree of first differencing involved

$\mathrm{q}=$ an order of the moving average part

The same stationarity and invertibility conditions that are used for autoregressive and moving average models apply to the ARIMA model.

With the backshift notation ${ }^{8}$, the equation $(2.1)$ can be written as:

$\left(1-\varphi_{1} \mathrm{~B}-\ldots \ldots . .-\varphi_{\mathrm{p}} \mathrm{B}^{\mathrm{p}}\right)(1-\mathrm{B})^{\mathrm{d}} \mathrm{y}_{\mathrm{t}}=\mathrm{c}+\left(1+\theta_{1} \mathrm{~B}+\ldots \ldots+\theta_{\mathrm{q}} \mathrm{B}^{\mathrm{q}}\right) \mathrm{e}_{\mathrm{t}}$
$\mathrm{AR}(\mathrm{p})$
d differences
$\operatorname{MA}(q)$

Special cases of the ARIMA model are shown in the following table:

Table 1. Special cases of the ARIMA model

\begin{tabular}{|l|l|l|l|l|}
\hline White noise & $\begin{array}{l}\text { Random walk } \\
\text { without drift }\end{array}$ & $\begin{array}{l}\text { Random walk with } \\
\text { drift }\end{array}$ & Autoregression & $\begin{array}{l}\text { Moving } \\
\text { Average }\end{array}$ \\
\hline $\begin{array}{l}\text { ARIMA } \\
(0,0,0)\end{array}$ & $\begin{array}{l}\text { ARIMA }(0,1,0) \text { with } \\
\text { no constant }\end{array}$ & $\begin{array}{l}\text { ARIMA }(0,1,0) \text { with } \\
\text { a constant }\end{array}$ & ARIMA $(p, 0,0)$ & $\begin{array}{l}\text { ARIMA } \\
(0,0, q)\end{array}$ \\
\hline
\end{tabular}

Source: Hyndman, G Athanasopoulos, Forecasting: principles and practice (An online textbook, Monash University 2012) Section 8: ARIMA models, Non-seasonal ARIMA models < https://www.otexts.org/fpp/8/5 > accessed 18 November 2013.

\footnotetext{
${ }^{8}$ The backward shift operator B (backshift notation), operating on $\mathrm{y}_{\mathrm{t}}$, has the effect of shifting the data back one period: $B y_{t}=y_{t-1}$. Two applications of $\mathrm{B}$ to $\mathrm{y}_{\mathrm{t}}$ shifts the data back two periods: $\mathrm{B}\left(\mathrm{B} \mathrm{y}_{\mathrm{t}}\right)=\mathrm{B}^{2} \mathrm{y}_{\mathrm{t}}=\mathrm{y}_{\mathrm{t}-2}$. The backward shift operator is convenient for describing the process of differencing. A first difference can be written as ${ }_{\mathrm{t}}=\mathrm{y}_{\mathrm{t}}-\mathrm{y}_{\mathrm{t}-1}=\mathrm{y}_{\mathrm{t}}-\mathrm{B} \mathrm{y}_{\mathrm{t}}=(1-\mathrm{B}) \mathrm{y}_{\mathrm{t}}$. In general, a $\mathrm{d}_{\mathrm{th}-\text { order }}$ difference can be written as $(1-\mathrm{B})^{\mathrm{d}} \mathrm{y}_{\mathrm{t}}$.
} 
ARIMA models are defined for stationary time series. The Augmented Dickey-Fuller (ADF) test and the Kwiatkowski-Phillips-Schmidt-Shin (KPSS) test are two popular tests which evaluate the stationarity of time series. ADF test tests the null hypothesis of a unit root in a time series sample against the alternative of stationarity of the time series. The KPSS test tests the null hypothesis that a time series is level or trend stationary against the alternative hypothesis that it is a non-stationary unit-root process (Hyndman and Athanasopoulos, 2012).

Once the model order (the values of $\mathrm{p}, \mathrm{d}$, and $\mathrm{q}$ ) has been indentified, the parameters including $\mathrm{c}, \varphi_{1}, \ldots \ldots \varphi_{\mathrm{p}}, \theta_{1}, \ldots \ldots \ldots, \theta_{\mathrm{q}}$ need to be estimated. A maximum likelihood estimation (MLE) is used to estimate ARIMA models in R program. This technique finds the values of the parameters which maximize the likelihood of obtaining data that have been observed. For ARIMA models, MLE is very similar to the least squares estimation that would be obtained by minimizing ${ }^{2}$. In practice, $\mathrm{R}$ reports the value of the $\log$ likelihood of the data which is the logarithm of the probability of the observed data coming from the estimated model. Thus, for given values of $\mathrm{p}, \mathrm{d}$ and $\mathrm{q}, \mathrm{R}$ tries to maximize the log-likelihood of the data when finding parameter estimates (Hyndman and Athanasopoulos, 2012).

Akaike's Information Criterion (AIC) is useful to determine the order of an ARIMA model. It can be written as $\mathrm{AIC}=-2 \log (\mathrm{L})+2(\mathrm{p}+\mathrm{q}+\mathrm{k}+1)$, where $\mathrm{L}$ is the likelihood of the data, $\mathrm{K}=1$ if $\mathrm{c} 0$ and $\mathrm{k}=0$ if $\mathrm{c}=0$. The last term in parentheses is the number of parameters in the model (including $\sigma^{2}$, the variance of the residuals). For ARIMA models, the corrected $\mathrm{AIC}$ can be written as $\mathrm{AIC}_{\mathrm{c}}=\mathrm{AIC}+$ and the Bayesian Information Criterion can be written as $\mathrm{BIC}=\mathrm{AIC}+\log (\mathrm{T})$ $(\mathrm{p}+\mathrm{q}+\mathrm{k}-1)$, where $\mathrm{T}$ is the number of time periods. Better models are obtained by minimizing either the $\mathrm{AIC}, \mathrm{AIC}_{c}$, or BIC (Hyndman and Athanasopoulos, 2012). It is important to note that $\mathrm{AIC}_{\mathrm{c}}$ is recommended to be used as the primary criterion in selecting the orders of an ARIMA model (Burnham \& Anderson, 2004; Brockwell \& Davis, 1991).

The point forecast, $\mathrm{T}+\mathrm{h} \mid \mathrm{T}$, is defined as the forecast of $\mathrm{T}_{\mathrm{h}} \mathrm{h}$ made at time T. Point forecasts can be calculated using the following three steps:

1 - Expanding the ARIMA equation so that $\mathrm{y}_{\mathrm{t}}$ is on the left hand side and all other terms are on the right.

2 - Rewriting the equation by replacing $\mathrm{t}$ by $\mathrm{T}+\mathrm{h}$.

3 - Replacing future observations on the right hand side of the equation by their forecasts, future errors by zero, and past errors by the corresponding residuals. Beginning with $h=1$, these steps are then repeated for $h=2,3, \ldots$ until all forecasts have been calculated (Hyndman and Athanasopoulos, 2012).

ARIMA forecast intervals require far more complex calculations than point forecasts. The first forecast interval is easily calculated. If is the standard deviation of the residuals, then a $95 \%$ forecast interval is given by $\mathrm{T}+1 \mid \mathrm{T} 1.96$ (Hyndman and Athanasopoulos, 2012). The correctness of the forecast intervals for ARIMA models relies on assumptions that the residuals of a fitted ARIMA model are uncorrelated and normally distributed (Hyndman and Athanasopoulos, 2012). 
The forecast intervals from ARIMA models increase as the forecast horizon increases. The behaviour of the forecast intervals is mainly affected by its stationarity. For stationary models (with $\mathrm{d}=0$ ), they initially increase and, accordingly, they will converge in the long term. For non-stationary models (d $>0$ ), the forecast intervals will continue growing in the long term (Hyndman and Athanasopoulos, 2012). ${ }^{9}$

\section{METHODOLOGY}

The $\mathrm{R}$ programming language ("forecast" package) is used to fit an ARIMA model to time series data and to do the forecasting. ${ }^{10}$ Box-Jenkins methodology is applied to select the appropriate ARIMA model and forecast the time series. The Box-Jenkins methodology is capable of identifying the correct model out of a large class of models through a systematic approach. It employs both statistical tests for evaluating the model and statistical measures of forecast uncertainty. This methodology is implemented through the following steps (Hyndman and Athanasopoulos, 2012):

1. The data is plotted, any unusual observations are identified, and patterns are evaluated.

2. If it is necessary, the data are transformed using a Box-Cox transformation ${ }^{11}$ to stabilize the variance and obtain normal distribution. ${ }^{12}$

3. The stationarity of data is assessed through Augmented Dickey-Fuller (ADF) and Kwiatkowski-Phillips-Schmidt-Shin (KPSS) tests. If the data are nonstationary, the first differences of data are taken until data are stationary.

4. The Autocorrelation function (ACF) and partial Autocorrelation function (PACF) ${ }^{13}$ plot of the data (or differenced data) are examined to determine

9 KP Burnham, DR Anderson, Model Selection and Multimodel Inference: A Practical Information-Theoretic Approach (2nd ed. Springer-Verlag 2002) Chapter 7 $<$ http://www.mun.ca/biology/quant/ModelSelectionMultimodelInference.pdf $>$ accessed 18 November 2013; RJ Hyndman, G Athanasopoulos, Forecasting: principles and practice (An online textbook, Monash University 2012) Section 8: ARIMA models <http://otexts.com/fpp $>$ accessed 18 November 2013.

${ }^{10}$ The R Project for Statistical Computing < http://www.r-project.org/> accessed 18 November 2013.

${ }^{11}$ The Box-Cox transformation transforms non-normally distributed data to a set of data that has approximately normal distribution using $\operatorname{Box} \operatorname{Cox}()$ function in $\mathrm{R}$. The Box-Cox transformation is defined as: if $\lambda$ is not equal to 0 , then $\operatorname{data}(\lambda)=$ and if $\lambda$ is equal to 0 , then data $(\lambda)=\log ($ data $)$. The transformation parameter $\lambda$ is estimated using automatic selection of Box Cox transformation parameter (BoxCox.lambda () function in R).

12 GEP Box, DR Cox, 'An analysis of transformations' (1964) (B) JRSS 26, 211-246 $<$ http://fisher.osu.edu/ schroeder.9/AMIS900/Box1964.pdf $>$ accessed 18 November 2013.

${ }^{13}$ Autocorrelation is the linear dependence of a variable with itself at two points in time. For stationary processes, autocorrelation between any two observations only depends on the time lag $\mathrm{h}$ between them. Define $\operatorname{Cov}\left(\mathrm{y}_{\mathrm{t}}, \mathrm{y}_{\mathrm{t}-\mathrm{h}}\right)=\gamma_{\mathrm{h}}$. Lag-h autocorrelation is given by $\rho_{\mathrm{h}}=\operatorname{Corr}\left(\mathrm{y}_{\mathrm{t}}, \mathrm{y}_{\mathrm{t}-\mathrm{h}}\right)=\gamma_{\mathrm{h}} / \gamma_{0}$. The denominator $\gamma_{0}$ is the lag 0 covariance that is the unconditional variance of the process. 
possible candidate models (e.g. to determine whether an AR (p) or MA (q) model is appropriate).

5. Using information criteria either the AIC, AICc, or BIC, chosen candidate models are tried to select a better model. Subsequently, a Student's t-test is used to test whether the coefficients of the selected model differ significantly from zero. ${ }^{14}$ If t-statistics indicates that any of the coefficients of the selected model fails to differ significantly from zero at the determined significance level (e.g. $\alpha=0.05$ ), that coefficient is set to zero and, consequently, the selected model is refitted.

6. Goodness of fit for the selected ARIMA model is checked through testing whether autocorrelation in the residuals is zero, testing the normality and homoscedasticity (constant variance) of residuals, and testing if the mean of residuals fluctuates around zero. It should be pointed out that obvious trends should be removed before normality is checked.

Goodness of fit determines if the residuals look like white noise or not. If goodness of fit fails and the residuals do not look like white noise, the procedure resumes from step 4 to find a modified model.

7. Once goodness of fit for the selected model is checked and it is suggested that the residuals look like white noise, forecasts are calculated. ${ }^{15}$

\section{THE MODEL AND THE RESULTS}

The data is extracted from OECD Statistics. ${ }^{16}$ Annual growth in GDP per hour worked (known as labour productivity annual growth rate) in Norway from 1971 to 2011 (figure 1) is the non-seasonal time series to which the ARIMA model is going to fit. ${ }^{17}$ Labour productivity growth time series seems to follow

Correlation between two variables can result from a mutual linear dependence on other variables. Partial autocorrelation is the autocorrelation between $\mathrm{y}_{\mathrm{t}}$ and $\mathrm{y}_{\mathrm{t}-\mathrm{h}}$ after removing any linear dependence on $\mathrm{y}_{1}, \mathrm{y}_{2}, \ldots, \mathrm{y}_{\mathrm{t}-\mathrm{h}+1}$. The partial lag-h autocorrelation is denoted $\varphi_{\mathrm{h}, \mathrm{h}}$. The use of these functions was introduced as part of the Box-Jenkins approach to time series modeling. By plotting the ACF, the appropriate lags $q$ in MA (q) could be determined. Plotting PACF could help determine the appropriate lags $\mathrm{p}$ in an AR (p) model. Both functions can be used in an extended $\operatorname{ARIMA~(p,~d,~q)~model~to~determine~lags~} q$ and lags $\mathrm{p}$.

14 The null hypothesis that a coefficient of the selected model is zero is rejected if the absolute value of t-statistics of that coefficient (the ratio of estimated coefficient to its standard error) is greater than $\mathrm{z}_{\alpha / 2}$ (For larger sample sizes, the t-test procedure gives almost identical $\mathrm{p}$-values as the Z-test procedure which is based on normal distribution approximation). In this case, a coefficient of the selected model differs significantly from zero.

${ }^{15}$ GEP Box, GM Jenkins, GC Reinsel, Time Series Analysis: Forecasting and Control (3rd ed. Englewood Cliffs, NJ: Prentice-Hall 1994) 32-33, 66, 68, 70-75, 188, 314-315, 547 $<$ http://eu.wiley.com/WileyCDA/WileyTitle/productCd-0470272848.html $>\quad$ accessed 18 November 2013; Hyndman (n 9).

${ }^{16}$ Labour productivity growth data in Norway extracted in January 2013 from OECD.Stat $<\underline{\text { http:// }}$ stats.oecd.org/> accessed 18 November 2013.

17 The data on labour productivity annual growth rate in Norway from 1971 till 2011 is available in Appendix B. 
a normal distribution ${ }^{18}$ and as figure 1 indicates, it shows no evidence of changing variance. Consequently, it is not necessary to use a Box-Cox transformation. In the next step, the stationarity of time series must be tested. The Norwegian labour productivity growth time series looks non-stationary as the series has a downward trend and it fluctuates up and down for long periods (figure 1). Based on the Augmented Dickey-Fuller (ADF) test, the null hypothesis of a unit root in labour productivity growth time series is failed to reject at the 5\% significance level. In addition, the Kwiatkowski-PhillipsSchmidt-Shin (KPSS) test indicates that the null hypothesis, that labour productivity growth time series is level stationary, is rejected in favour of an alternative hypothesis that it is a non-stationary unit root process at the $5 \%$ significance level. Subsequently, based on the ADF test and KPSS test at the 5\% significance level, the labour productivity growth series is a non-stationary unit root process. Labour productivity growth series needs to be differenced in order to be stationary. Based on ADF and KPSS tests, the first difference of the labour productivity growth series is a stationary process at the 5\% significance level (more details on this can be found in Appendix C).

Therefore, the Norwegian labour productivity growth time series is difference stationary. It is integrated of order one $(\mathrm{I}(1))$ and it has a unit root. ${ }^{19}$

After having Norwegian labour productivity growth time series transformed into a stationary series using the differencing method, an appropriate ARIMA model is selected.

First of all, the Autocorrelation Function (ACF) and Partial Autocorrelation Function (PACF) plot for the differenced labour productivity growth time series are examined. Figure 2 shows the time plot and ACF and PACF plots (lags 1-20) for the differenced Norwegian labour productivity growth time series. ${ }^{20}$

${ }^{18}$ The Shapiro-Wilk normality test on labour productivity growth series indicates that the null hypothesis of normality is failed to reject at $5 \%$ significant level ( $p$-value $=0.1557>0.05$ ).

19 JD Hamilton, Time Series Analysis (Princeton University Press New Jersey 1994) 514-528 $<$ http://press.princeton.edu/titles/5386.html $>$ accessed 18 November 2013; A Coghlan, A Little Book of R For Time Series (Release 0.1. University College Cork, Cork, Ireland 2011) 13-65 $<$ http://stamash.org/hub/wp-content/uploads/2012/09/TimeSeries.pdf $>$ accessed 18 November 2013; Hyndman (n 9); DA Dickey, WA Fuller WA, 'Distribution of the estimators for autoregressive time series with a unit root' (1979) Journal of the American Statistical Association 74, 427-431 <http://www.deu.edu.tr/userweb/onder.hanedar/dosyalar/1979.pdf $>$ accessed 18 November 2013; SE Said, DA Dickey, 'Testing for Unit Roots in Autoregressive-Moving Average Models of Unknown Order' (1984) (3) Biometrika 71, 599-607. doi:10.1093/biomet/71.3.599 $<$ http://www.ssc.wisc.edu/ bhansen/718/SaidDickey1984.pdf> accessed 18 November 2013; D Kwiatkowski, PCB Phillips, P Schmidt, Y Shin, 'Testing the Null Hypothesis of Stationarity against the Alternative of a Unit Root' (1992) Journal of Econometrics 54, 159-178

$<$ http://www.ccee.edu.uy/ensenian/catmetec/material/KPSS.pdf > accessed 18 November 2013

${ }^{20}$ The values of autocorrelations and partial autocorrelations are presented in Appendix D. 
Figure 2. Time plot and ACF and PACF plots (lags 1-20) for the differenced Norwegian labour productivity growth time series

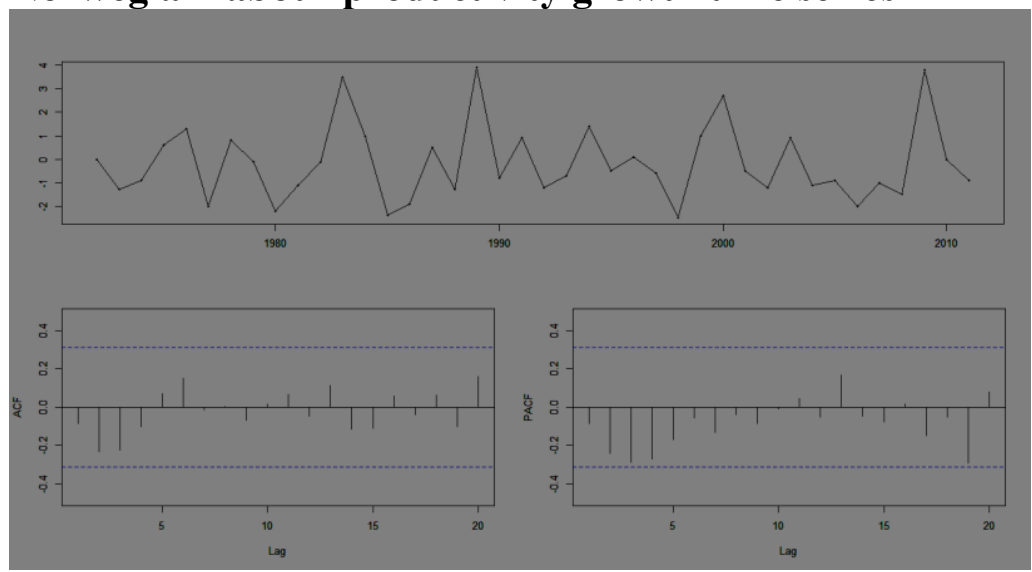

As figure 2 indicates, autocorrelations between lags 1-20 do not exceed the significant bounds. The ACF looks sinusoidal. Although the partial autocorrelations between lags 1-20 do not exceed the significant bounds, after the third lag (which is very close to the lower significance bound), they tail off to zero. As figure 2 shows, the differenced Norwegian labour productivity growth time series fluctuates around zero. This fact suggests that the constant term in ARIMA model is equal to zero. Therefore, an initial candidate model is an ARIMA $(3,1,0)$ without constant.

Candidate models include ARIMA (p, 1, q) models without constant, where $\mathrm{p}$ is between 0 and 3 inclusively, and $\mathrm{q}$ varies between 0 and 1 inclusively. ${ }^{21}$ The information criteria in Table 2 are used to find a better model.

It is concluded that $\operatorname{ARIMA}(1,1,1)$ with no constant haa a relative preference over other models since it has smaller AICc. On the other hand, the auto. arima () function in the R program ${ }^{22}$ also identifies ARIMA $(1,1,1)$ with no constant as an appropriate model. ${ }^{23}$

Considering equation (2), ARIMA $(1,1,1)$ with no constant can be written as follows:

$(1-\operatorname{ar} 1 \mathrm{~B})(1-\mathrm{B}) \mathrm{y}_{\mathrm{t}}=\left(1+\mathrm{ma1B}^{\mathrm{B}}\right) \mathrm{e}_{\mathrm{t}}$

$\left(1-B-\operatorname{ar} 1 B+\operatorname{ar} 1 B^{2}\right) y_{t}=(1+m a 1 B) e_{t}$

$\mathrm{y}_{\mathrm{t}}-\mathrm{y}_{\mathrm{t}-1}-\operatorname{ar} 1 \mathrm{y}_{\mathrm{t}-1}+\operatorname{ar} 1 \mathrm{y}_{\mathrm{t}-2}=\mathrm{e}_{\mathrm{t}}+$ male $_{\mathrm{t}-1}$

The final model is: $\mathrm{y}_{\mathrm{t}}=(1+\operatorname{ar} 1) \mathrm{y}_{\mathrm{t}-1}-\operatorname{ar} 1 \mathrm{y}_{\mathrm{t}-2}+$ male $_{\mathrm{t}-1}+\mathrm{e}_{\mathrm{t}}$

Note: ar1 is the first autoregressive coefficient and mal is the first moving average coefficient.

${ }^{21}$ PJ Brockwell, RA Davis, Introduction to Time Series and Forecasting (Second edition, Springer -Verlag, New York 2002) 238-250, 273-320<http://www.masys.url.tw/Download/2002Brockwell-Introduction\%20Time\%20Series\%20and\%20Forecasting.pdf $>\quad$ accessed 18 November 2013; Coghlan (n 19); Hyndman (n 9).

${ }^{22}$ The auto.arima() function in $\mathrm{R}$ uses a variation of the Hyndman and Khandakar algorithm which combines unit root tests, minimization of the AICc and MLE to obtain an ARIMA model. ${ }^{23}$ Hyndman (n 9). 
Table 2. Information criteria helping find an appropriate model

\begin{tabular}{|l|l|l|l|l|}
\hline \multirow{2}{*}{ ARIMA Model } & \multicolumn{4}{|c|}{ Information Criteria } \\
\cline { 2 - 5 } & sigma^2 & $\begin{array}{l}\text { Log } \\
\text { likelihood }\end{array}$ & AIC & AICc \\
\hline ARIMA (3, 1, 0) & 2.21 & -72.8 & 153.61 & 154.75 \\
\hline ARIMA (2, 1, 0) & 2.411 & -74.41 & 154.83 & 155.5 \\
\hline ARIMA (1, 1, 0) & 2.549 & -75.47 & 154.94 & 155.27 \\
\hline ARIMA (0, 1, 0) & 2.564 & -75.59 & 153.17 & 153.28 \\
\hline ARIMA (0, 1, 1) & 2.531 & -75.34 & 154.69 & 155.01 \\
\hline ARIMA (1, 1, 1) & 2.26 & -73.24 & 152.49 & 153.16 \\
\hline ARIMA (2, 1, 1) & 2.146 & -72.27 & 152.53 & 153.67 \\
\hline ARIMA (3, 1, 1) & 2.091 & -71.8 & 153.59 & 155.36 \\
\hline
\end{tabular}

The result of ARIMA $(1,1,1)$ with no constant for Norwegian labour productivity growth time series is as follows:

Series: Labourproduc11

$\operatorname{ARIMA}(1,1,1)$

$\begin{array}{lcl} & \text { ar1 } & \text { ma1 } \\ \text { coefficient } & 0.5231 & -0.8312 \\ \text { standard error } & 0.2074 & 0.1328 \\ \text { t-statistics } & 2.5222 & -6.259 \\ \text { p-value } & 0.0117 & <0.01\end{array}$

sigma $^{\wedge} 2$ estimated as 2.26: $\log$ likelihood $=-73.24$

$\mathrm{AIC}=152.49 \quad \mathrm{AICc}=153.16 \quad \mathrm{BIC}=157.56$

The final model is: $\mathrm{y}_{\mathrm{t}}=(1.5231) \mathrm{y}_{\mathrm{t}-1}-(0.5231) \mathrm{y}_{\mathrm{t}-2}+(-0.8312) \mathrm{e}_{\mathrm{t}-1}+\mathrm{e}_{\mathrm{t}}$, where $\mathrm{y}_{\mathrm{t}}$ is the Norwegian labour productivity growth time series in year $t$, and $e_{t}$ is the white noise.

The result of ARIMA $(1,1,1)$ with no constant model indicates that the first autoregressive coefficient (ar1) and the first moving average coefficient (ma1) differ significantly from zero at the 0.05 significance level since the absolute value of t-statistics (the ratio of estimated coefficient to its standard error) of the first autoregressive coefficient and the first moving average coefficient are greater than 1.96 (2.52 and 6.26 respectively $)^{24}$.

After having the best model selected out of the candidate models and having the statistical significance of its coefficients tested, its goodness of fit is checked.

\footnotetext{
${ }^{24} \mathrm{P}$-values from t-statistics are less than $0.05(0.01$ and $<0.01$ respectively).
} 
In order to check that there is no autocorrelation in residuals, the LjungBox test and the ACF plot of the residuals from the selected model are applied. The Ljung-Box test is a portmanteau test since it tests the overall randomness based on a number of lags instead of testing randomness at each distinct lag. The Ljung-Box test evaluates the null hypothesis that a series of residuals shows no autocorrelation for a fixed number of lags against the alternative that some autocorrelation coefficient is non-zero (Box, Jenkins, and Reinsel, 1994; Box and Pierce, 1970). ${ }^{25}$ The Ljung-Box test indicates that the null hypothesis of no autocorrelation in residuals from $\operatorname{ARIMA}(1,1,1)$ with no constant for lags 1 -20 is failed to reject at the 0.05 significance level ( $p$-value $=0.8241>0.05$, and $\left.\mathrm{Q}=12.4337<\mathrm{X}^{2}{ }_{0.05,18}=28.87\right)$. In addition, the ACF plot of the residuals from the selected model for lags 1-20 shows all correlations are within the threshold limits (figure 3). This fact indicates that the residuals are behaving like white noise. According to its definition, a white noise process is uncorrelated in time. Based on the Ljung-Box test and ACF plot of the residuals, it is concluded that there is no evidence for non-zero autocorrelation in residuals of the fitted model at lags $1-20$.

\section{Figure 3.The ACF plot of the residuals from ARIMA $(1,1,1)$ with no} constant for lags 1-20

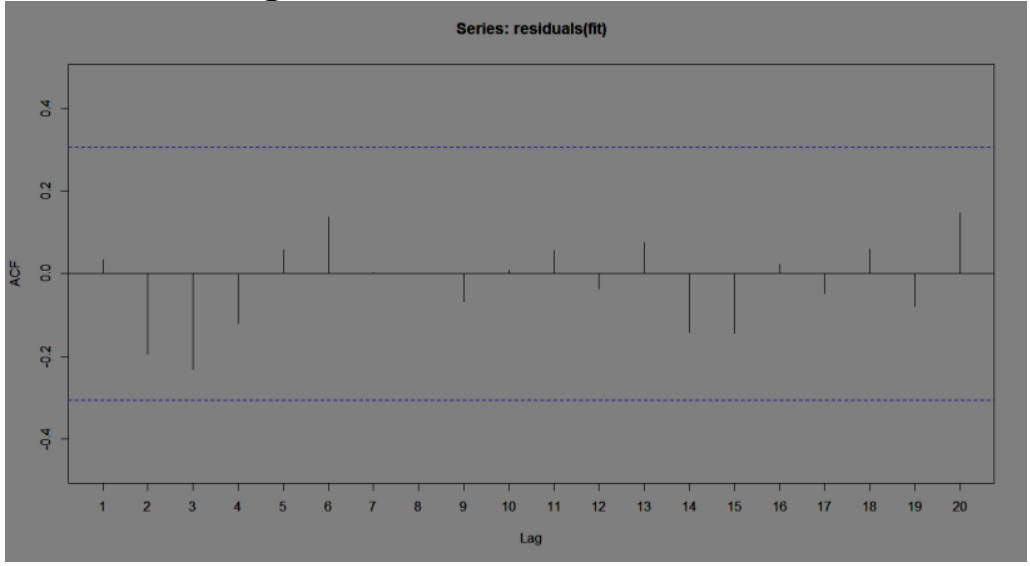

In order to check whether the residuals from ARIMA $(1,1,1)$ with no constant have normal distribution, the Shapiro-Wilk normality test of residuals and normal probability plot of residuals are applied. The Shapiro-Wilk normality test tests the null hypothesis that the samples come from a normal distribution against the alternative hypothesis the samples do not come from a normal

\footnotetext{
${ }^{25}$ Box (n 15); GEP Box, DA Pierce, 'Distribution of Residual Autocorrelations in AutoregressiveIntegrated Moving Average Time Series Models' (1970) Journal of the American Statistical Association 65, 1509-1526

< http://www.stat.purdue.edu/ mlevins/STAT598K_2012/Box_Pierce_1970.pdf > accessed 18 November 2013.
} 
distribution (Shapiro and Wilk, 1965). ${ }^{26}$ Based on the results of the Shapiro-Wilk normality test, the null hypothesis of normality of residuals is failed to reject at the 0.05 significance level ( $\mathrm{W}$ is large and $\mathrm{p}$-value $=0.1539>0.05$ ). The normal probability plot evaluates whether the data is normally distributed through plotting the data against a sample from theoretical normal distribution so that the points should form an approximately straight line. The departure of points from the straight line suggests departure from normality (Chambers, Cleveland, Kleiner, and Tukey, 1983). ${ }^{27}$ The normal probability plot of residuals (figure 4) indicates that since most of points lie close to a straight line, the data is almost consistent with a sample from normal distribution. Therefore, based on ShapiroWilk normality test and normal probability plot, it is reasonable to say that the residuals are approximately normally distributed.

To check whether residuals from ARIMA $(1,1,1)$ with no constant have constant variance, and their mean varies around zero, a time plot of standardized residuals from this model is used (figure 5). As figure 4.4 indicates, standardized residuals of the selected model seem to have approximately constant variance over time (homoscedasticity) although the size of fluctuations at some years is much bigger compared to others. Furthermore, standardized residuals fluctuate around zero. The goodness of fit evaluation suggests that the residuals from $\operatorname{ARIMA}(1,1,1)$ with no constant look like white noise. ${ }^{28}$

Figure 4. Normal probability plot of the residuals from ARIMA $(1,1,1)$ with no constant

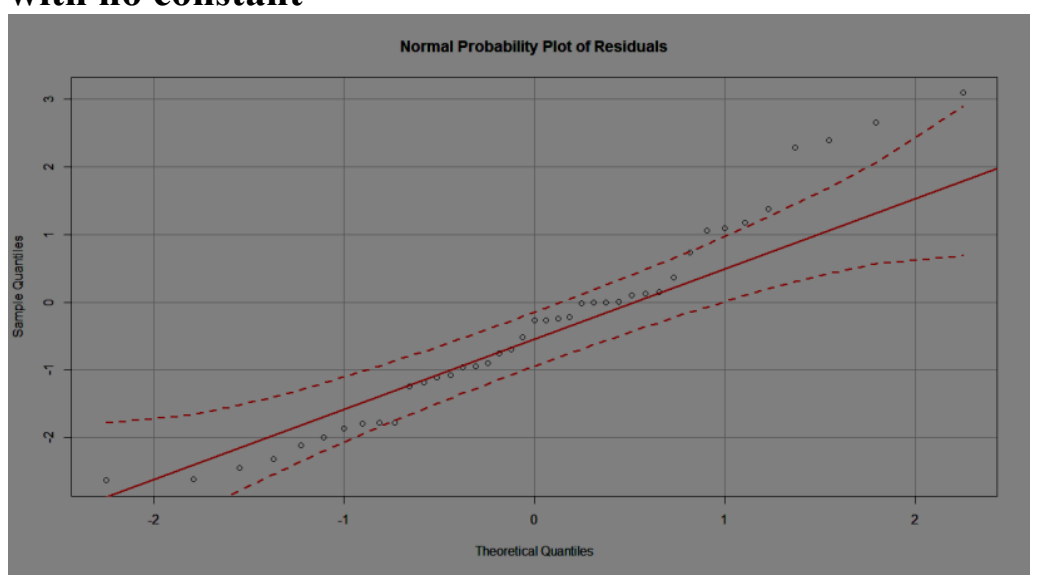

${ }^{26}$ SS Shapiro, MB Wilk, 'An analysis of variance test for normality (complete samples)' (1965) (3-4) Biometrika 52, 591-611. doi:10.1093/biomet/52.3-4.591 $<$ http://sci2s.ugr.es/keel/pdf/algorithm/articulo/shapiro1965.pdf $>$ accessed 18 November 2013. 27 J Chambers, W Cleveland, B Kleiner, P Tukey, Graphical Methods for Data Analysis (Wadsworth \& Brooks/Cole, Pacific Grove, CA 1983) $<$ http://stat.belllabs.com/wsc/papersbooks.pdf> accessed 18 November 2013.

${ }^{28}$ In addition to measures mentioned above, in Appendix E, fitted values of labour productivity growth versus observed values are shown graphically. 
Figure 5. Time plot of standardized residuals from $\operatorname{ARIMA}(1,1,1)$ with no constant

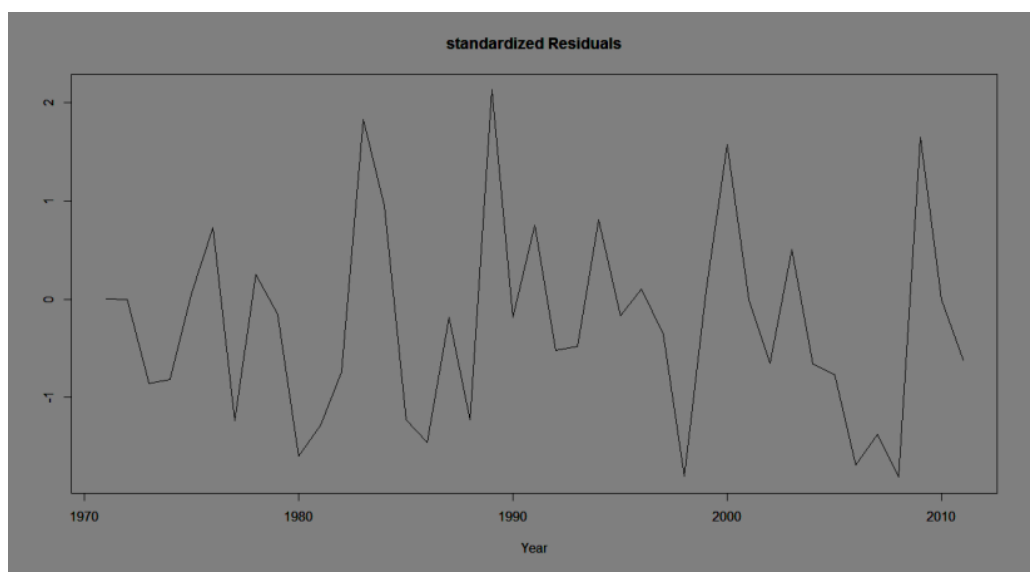

After having goodness of fit checked, using estimated selected ARIMA model (ARIMA $(1,1,1)$ with no constant) labour productivity growth in Norway for the next 10 years is predicted. In addition, $80 \%$ and $95 \%$ forecast intervals for these forecasts are obtained (Table 3).

Table 3. Point forecasts and their $80 \%$ and $95 \%$ forecast intervals for labour productivity growth in Norway for the next 10 years using ARIMA $(1,1,1)$ with no constant

\begin{tabular}{|l|l|l|l|l|l|}
\hline Year & $\begin{array}{l}\text { Point } \\
\text { Forecast }\end{array}$ & Lo 80 & Hi 80 & Lo 95 & Hi 95 \\
\hline $\mathbf{2 0 1 2}$ & -0.2227 & -2.1495 & 1.7040 & -3.1695 & 2.7240 \\
\hline $\mathbf{2 0 1 3}$ & -0.0777 & -2.4207 & 2.2653 & -3.6610 & 3.5056 \\
\hline $\mathbf{2 0 1 4}$ & -0.0018 & -2.5583 & 2.5546 & -3.9115 & 3.9079 \\
\hline $\mathbf{2 0 1 5}$ & 0.0379 & -2.6594 & 2.7351 & -4.0872 & 4.1630 \\
\hline $\mathbf{2 0 1 6}$ & 0.0586 & -2.7478 & 2.8651 & -4.2335 & 4.3507 \\
\hline $\mathbf{2 0 1 7}$ & 0.0695 & -2.8305 & 2.9695 & -4.3657 & 4.5047 \\
\hline $\mathbf{2 0 1 8}$ & 0.0752 & -2.9099 & 3.0602 & -4.4901 & 4.6404 \\
\hline $\mathbf{2 0 1 9}$ & 0.0781 & -2.9868 & 3.1431 & -4.6093 & 4.7656 \\
\hline $\mathbf{2 0 2 0}$ & 0.0797 & -3.0618 & 3.2211 & -4.7248 & 4.8841 \\
\hline $\mathbf{2 0 2 1}$ & 0.0805 & -3.1349 & 3.2959 & -4.8370 & 4.9980 \\
\hline
\end{tabular}

Figure 6 displays the observed values of Norwegian time-series labour productivity growth in the period 1971-2011 (in-sample period) together with Norwegian time-series labour productivity growth forecasts and their $80 \%$ and $95 \%$ forecast intervals for the next 10 years (out-of-sample period) using the selected ARIMA model. The forecasts for the period 2012-2021 are plotted as a blue line, the $80 \%$ forecast interval as an orange shaded area, and the $95 \%$ forecast interval as a yellow shaded area. 
Figure 6. Observed values of Norwegian time-series labour productivity growth in the period 1971-2011 (in-sample period) together with its forecast time-series for the period 2012-2021 (out-of-sample period) using ARIMA $(1,1,1)$ with no constant

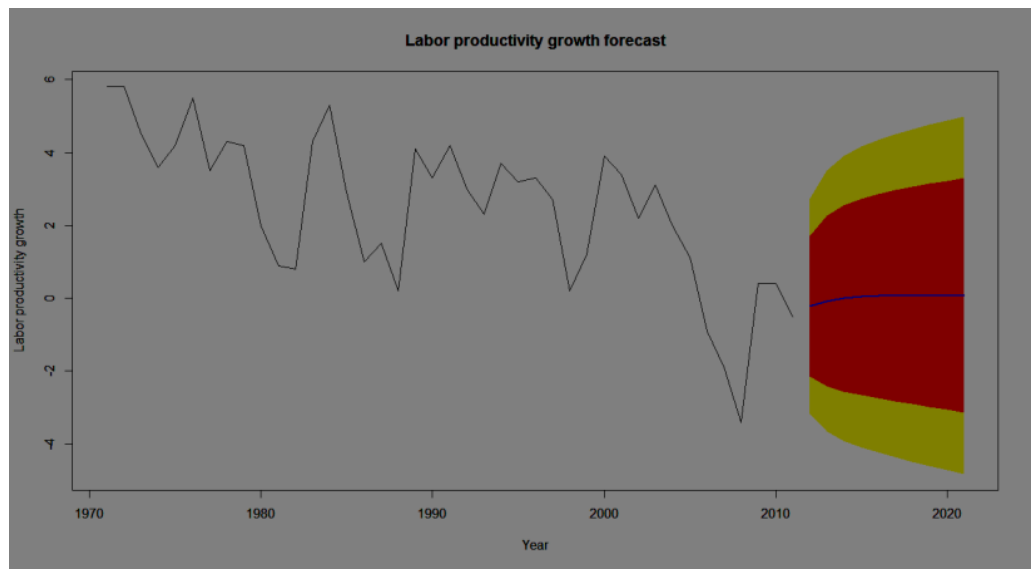

As figure 6 shows, Norwegian labour productivity growth time series continues increasing very slowly and ultimately it goes to a non-zero constant in the forecast period (2012-2021) following its recovery after $2008 .^{29}$

\section{DiscuSsion AND CONCLUSION}

Norwegian time-series labour productivity growth is difference stationary. It is integrated of order one (I (1)) and it has a unit root then. Through Box-Jenkins methodology, ARIMA model is fitted to Norwegian labour productivity growth time series.

${ }^{29}$ Hamilton (n 19) 43-117, 514-528; Brockwell (n 21); C Kleiber, A Zeileis, Applied Econometrics with $R$ (Springer -Verlag, New York 2008) $<$ http://uosis.mif.vu.lt/ rlapinskas/2012-2013/Ekonometrija\%203k/KleibZeil\%20-

\%20AER.pdf $>$ accessed 18 November 2013; PSP Cowpertwait, AV Metcalfe, Introductory Time Series with $R$ (Springer-Verlag, New York 2009)121-128, 137-140 $<$ http://www.springer.com/statistics/statistical+theory+and+methods/book/978-0-387-88697-8> accessed 18 November 2013; Coghlan (n 19); RH Shumway, DS Stoffer, Time Series Analysis and Its Applications: With R Examples (Springer Texts in Statistics 2010, 3rd ed. 2011) XII, chapter 3 , $83-154$ $<$ http://www.springer.com/statistics/statistical+theory+and+methods/book/978-0-387-36276-2> accessed 18 November 2013; Hyndman (n 9); H Akaike, 'A new look at the statistical model identification' (1974) (6) IEEE Transactions on Automatic Control 19, 716-723 $<$ http://ieeexplore.ieee.org/xpl/freeabs_all.jsp?arnumber=1100705\&abstractAccess=no\&userTy pe=inst $>$ accessed 18 November 2013. 
As AICs (preferred information criterion) indicates, $\operatorname{ARIMA}(1,1,1)$ with no constant is selected as an appropriate model among the candidates. The statistical significance test of coefficients of the selected model indicates that all coefficients are significant at the 5\% level. The auto.arima() function in $\mathrm{R}$ also delivers exactly the same model. If BIC criterion which penalizes the number of parameters is used, $\operatorname{ARIMA}(0,1,0)$ with no constant (random walk without a drift) is obtained as an appropriate model.

From statistical perspective, $\operatorname{ARIMA}(0,1,0)$ with no constant could be the second best model since it not only has the smallest BIC, but it has the second smallest AIC and AICc. In Appendix F, the forecast for time-series labour productivity growth in Norway for the period 2012-2021 using ARIMA $(0,1,0)$ with no constant (random walk without a drift) is displayed graphically. However, the random walk model has two obvious weaknesses: 1) The forecasts for future growth are all negative (It is equal to -0.5), which is not in agreement with the theory of economic growth through technological advance 2) The process is not stationary and confidence intervals for the growth rate become increasingly wide, which is not in accordance with the intuition that over time the labour productivity growth rate varies within fairly narrow bounds. Consequently, this random walk model is inappropriate from economic perspective.

The goodness of fit of the selected model (ARIMA $(1,1,1)$ with no constant) is checked by testing if autocorrelation in its residuals is zero, testing the normality and homoscedasticity of its residuals, and testing if the mean of residuals varies around zero. The Ljung-Box test indicates that the null hypothesis of no autocorrelation in residuals from ARIMA $(1,1,1)$ with no constant for lags $1-20$ is failed to reject at the 5\% significance level. The ACF plot of residuals for lags 1-20 shows that residuals are behaving like white noise. Therefore, it is concluded that there is no evidence for non-zero autocorrelation in residuals from the selected model at lags 1-20. The Shapiro-Wilk normality test of residuals from the selected model (at the 5\% significance level) and normal probability plot of residuals show that it is plausible that the residuals are approximately normally distributed. The time plot of standardized residuals data suggests that residuals have approximately constant variance over time. In addition, standardized residuals fluctuate around zero (indicating that the mean of residuals varies around zero). As a result, it is concluded that $\operatorname{ARIMA}(1,1,1)$ with no constant is well fitted and provides an adequate predictive model for labour productivity growth, which probably cannot be modified further. In addition, the assumptions that the $80 \%$ and $95 \%$ forecast intervals were based on (that the residuals from the selected model are uncorrelated and normally distributed) are valid at the 0.05 significance level.

Labour productivity growth is forecasted for the period 2012-2021 using $\operatorname{ARIMA}(1,1,1)$ with no constant. The constant $\mathrm{c}$ (intercept) has an important effect on the long-term forecasts obtained from the ARIMA models. If $\mathrm{c}=0$ (zero intercept) and $\mathrm{d}=1$ (series is non-stationary), the long-term forecasts will go to a non-zero constant (Hyndman and Athanasopoulos, 2012). 
By estimating the forecast for labour productivity growth in Norway for the period 2012-2021 (figure 6) and also for the periods 2012-2031 and 2012-2041 (displayed in

Appendix G) using the selected model (ARIMA $(1,1,1)$ with no constant), It is empirically proven that the long-term forecasts for non-stationary models with zero intercept will go to a non-zero constant as the forecast horizon increases. The forecast made using ARIMA $(0,1,0)$ with no constant (displayed in Appendix F) also empirically approves this fact.

For both ARIMA $(1,1,1)$ with no constant and $\operatorname{ARIMA}(0,1,0)$ with no constant, forecast intervals increase as the forecast horizon increases. As a result, the fact that for non-stationary models the forecast intervals continue growing in the long-term is empirically proven.

As discussed before, there seemed to be a change in the Norwegian labour productivity growth rate (a fall in the growth rate) in the middle of the 2000s, before a slight recovery at the end of the period under consideration (1971-2011) occurred. The 2007-2009 financial and economic crisis in Norway (which resulted from the banking crisis) caused an even greater drop in labour productivity growth to the extent that in 2008it reached its lowest point in the previous three decades. After 2008 labour productivity growth started increasing. Norwegian labour productivity growth continues increasing very slowly and ultimately it reaches a non-zero constant in the forecast period (2012-2021) and also over longer periods (2012-2031 and 2012-2041) following its recovery after 2008. A decrease in investment leads to slowed down technological development in the longer term in a knowledge-based economy like the Norwegian economy, which is characterised by complex links between service and manufacturing activities. Therefore, it might initially be concluded that slow technological development as a result of limited access to funds due to the 2007-2009 financial and economic crisis in Norway could explain a slowdown in the recovery of labour productivity growth in the forecast period (2012-2021) and over longer periods (2012-2031 and 2012-2041). Although the ARIMA $(1,1,1)$ with no constant gives more sensible predictions than random walk without a drift (ARIMA $(0,1,0)$ with no constant), this model also seems to be limited in being able to describe the data. Firstly, the short-term labour productivity growth rate is predicted to be less than $0.1 \%$. This seems out of line with the data observed over the 41-year period as a whole and overly dependent on the data from the financial and economic crisis period. Also, the 95\% confidence interval 2-3 years (points) after the last observation already covers the range of observations over the last 41 years, which suggests that picking a number randomly from this range would be just as good a method as using a time-series model. The reason for this almost certainly results from the fact that the crisis has changed the underlying process which the labour productivity growth rate followed in the immediatelypreceding period. Furthermore, the period immediately before the crisis also covers the technological revolution which can be considered as a contributing factor to labour productivity growth in Norway. Therefore, it seems unlikely that a univariate labour productivity growth time series will be rich enough to 
describe the variation in the data. From the data and the analysis performed, it seems plausible to conclude that the crisis has changed the underlying process determining the labour productivity growth rate (at least in the short-term) and thus, forecasts based on such models are rather unreliable. Finally, it is important to note that a reliable and effective model which predicts the labour productivity growth in Norway through employing relevant time series is subject to future research.

\section{APPENDIX}

\section{Appendix A}

Labour productivity growth time series plot in some major industrial countries, 1971-2011

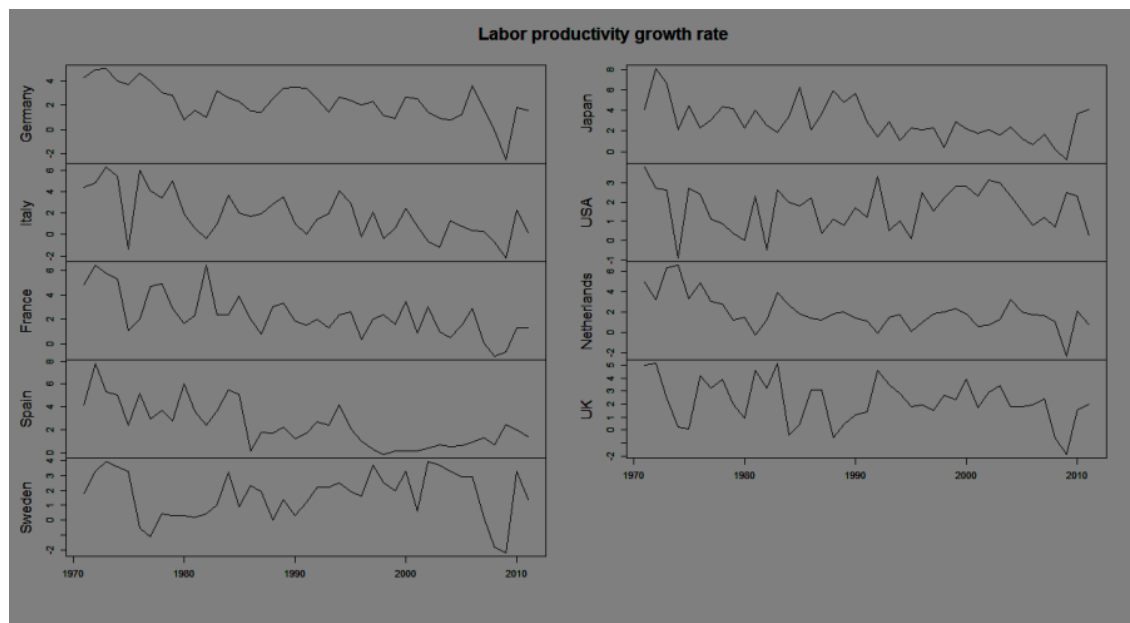

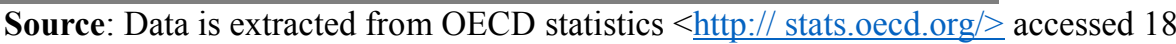
November 2013.

\section{Appendix B}

Labour productivity annual growth rate in Norway from 1971 till 2011:

\begin{tabular}{|l|l|l|c|c|c|c|c|c|c|c|c|}
\hline 1971 & $\mathbf{1 9 7 2}$ & $\mathbf{1 9 7 3}$ & $\mathbf{1 9 7 4}$ & $\mathbf{1 9 7 5}$ & $\mathbf{1 9 7 6}$ & $\mathbf{1 9 7 7}$ & $\begin{array}{l}\mathbf{1 9 7} \\
\mathbf{8}\end{array}$ & $\mathbf{1 9 7 9}$ & $\mathbf{1 9 8 0}$ & $\mathbf{1 9 8 1}$ & $\mathbf{1 9 8 2}$ \\
\hline 5.8 & 5.8 & 4.5 & 3.6 & 4.2 & 5.5 & 3.5 & 4.3 & 4.2 & 2.0 & 0.9 & 0.8 \\
\hline $\mathbf{1 9 8 3}$ & $\mathbf{1 9 8 4}$ & $\mathbf{1 9 8 5}$ & $\mathbf{1 9 8 6}$ & $\mathbf{1 9 8 7}$ & $\mathbf{1 9 8 8}$ & $\mathbf{1 9 8 9}$ & $\mathbf{1 9 9 0}$ & $\mathbf{1 9 9 1}$ & $\mathbf{1 9 9 2}$ & $\mathbf{1 9 9 3}$ & $\mathbf{1 9 9 4}$ \\
\hline 4.3 & 5.3 & 2.9 & 1.0 & 1.5 & 0.2 & 4.1 & 3.3 & 4.2 & 3.0 & 2.3 & 3.07 \\
\hline $\mathbf{1 9 9 5}$ & $\mathbf{1 9 9 6}$ & $\mathbf{1 9 9 7}$ & $\mathbf{1 9 9 8}$ & $\mathbf{1 9 9 9}$ & $\mathbf{2 0 0 0}$ & $\mathbf{2 0 0 1}$ & $\mathbf{2 0 0 2}$ & $\mathbf{2 0 0 3}$ & $\mathbf{2 0 0 4}$ & $\mathbf{2 0 0 5}$ & $\mathbf{2 0 0 6}$ \\
\hline 3.2 & 3.3 & 2.7 & 0.2 & 1.2 & 3.9 & 3.4 & 2.2 & 3.1 & 2.0 & 1.1 & -0.9 \\
\hline $\mathbf{2 0 0 7}$ & $\mathbf{2 0 0 8}$ & $\mathbf{2 0 0 9}$ & $\mathbf{2 0 1 0}$ & $\mathbf{2 0 1 1}$ & & & & & & & \\
\hline-1.9 & -3.4 & 0.4 & 0.4 & -0.5 & & & & & & & \\
\hline
\end{tabular}




\section{Appendix C}

The result of the Augmented Dickey Fuller test (ADF) for labour productivity growth time series:

Augmented Dickey-Fuller Test

data: Labourproduc11

Dickey-Fuller $=-2.5419$, Lag order $=3, \mathrm{p}$-value $=0.3604$

alternative hypothesis: stationary

Conclusion: The p-value of the ADF test (0.3604) is greater than 0.05 . Therefore, the null hypothesis of a unit root in labour productivity growth time series is failed to reject against the alternative that the series is stationary at the $5 \%$ significance level.

The result of the KPSS test for labour productivity growth time series:

KPSS Test for level stationarity

data: Labourproduc11

KPSS Level $=1.0548$, Truncation lag parameter $=1, \mathrm{p}$-value $=0.01$

Warning message:

In kpss.test(Labourproduc11, null = "Level") :

p-value smaller than printed p-value

Conclusion: The p-value of the KPSS test is smaller than 0.05. Therefore, the null hypothesis that labour productivity growth time series is level stationary is rejected in favour of alternative hypothesis that it is a non-stationary unit-root process at the $5 \%$ significance level.

The result of the Augmented Dickey Fuller test (ADF) for the differenced labour productivity growth time series:

Augmented Dickey-Fuller Test

data: diff(Labourproduc11)

Dickey-Fuller $=-5.0319$, Lag order $=3, p$-value $=0.01$

alternative hypothesis: stationary

Warning message:

In adf.test(diff(Labourproduc11)) : p-value smaller than printed p-value

Conclusion: The p-value of the ADF test is smaller than 0.05. Therefore, the null hypothesis of a unit root in the differenced labour productivity growth time series is rejected in favour of the alternative that the series is stationary at the $5 \%$ significance level.

The result of the KPSS test for the differenced labour productivity growth time series:

KPSS Test for level stationarity

data: diff(Labourproduc11)

KPSS Level $=0.0291$, Truncation lag parameter $=1, \mathrm{p}$-value $=0.1$

Warning message: 
In kpss.test(diff(Labourproduc11)) : p-value greater than printed p-value Conclusion: The p-value of the KPSS test is greater than 0.05 . Then, the null hypothesis that the differenced labour productivity growth time series is level stationary is failed to reject against the alternative hypothesis that it is a nonstationary unit-root process at the 5\% significance level.

Appendix D

Autocorrelations for the differenced labour productivity growth time series by lag

\begin{tabular}{|c|c|c|c|c|c|c|c|c|c|c|}
\hline $\mathbf{0}$ & $\mathbf{1}$ & $\mathbf{2}$ & $\mathbf{3}$ & $\mathbf{4}$ & $\mathbf{5}$ & $\mathbf{6}$ & $\mathbf{7}$ & $\mathbf{8}$ & $\mathbf{9}$ & $\mathbf{1 0}$ \\
\hline 1.000 & -0.086 & -0.231 & -0.223 & -0.103 & 0.070 & 0.152 & -0.014 & 0.002 & -0.070 & 0.015 \\
\hline $\mathbf{1 1}$ & $\mathbf{1 2}$ & $\mathbf{1 3}$ & $\mathbf{1 4}$ & $\mathbf{1 5}$ & $\mathbf{1 6}$ & $\mathbf{1 7}$ & $\mathbf{1 8}$ & $\mathbf{1 9}$ & $\mathbf{2 0}$ & \\
\hline 0.066 & -0.049 & 0.114 & -0.112 & -0.112 & 0.060 & -0.039 & 0.062 & -0.100 & 0.160 & \\
\hline
\end{tabular}

Partial Autocorrelations for the differenced labour productivity growth time series by lag

\begin{tabular}{|c|c|c|c|c|c|c|c|c|c|c|}
\hline $\mathbf{1}$ & $\mathbf{2}$ & $\mathbf{3}$ & $\mathbf{4}$ & $\mathbf{5}$ & $\mathbf{6}$ & $\mathbf{7}$ & $\mathbf{8}$ & $\mathbf{9}$ & $\mathbf{1 0}$ & $\mathbf{1 1}$ \\
\hline-0.086 & -0.240 & -0.287 & -0.268 & -0.168 & -0.054 & -0.133 & -0.040 & -0.086 & -0.010 & 0.044 \\
\hline $\mathbf{1 2}$ & $\mathbf{1 3}$ & $\mathbf{1 4}$ & $\mathbf{1 5}$ & $\mathbf{1 6}$ & $\mathbf{1 7}$ & $\mathbf{1 8}$ & $\mathbf{1 9}$ & $\mathbf{2 0}$ & & \\
\hline-0.051 & 0.169 & -0.046 & -0.076 & 0.014 & -0.146 & -0.053 & -0.290 & 0.08 & & \\
\hline
\end{tabular}

Appendix E

Observed values of Norwegian labour productivity growth time series between 1971-2011 versus its fitted values in the same period using the selected ARIMA model (ARIMA $(1,1,1)$ with no constant)

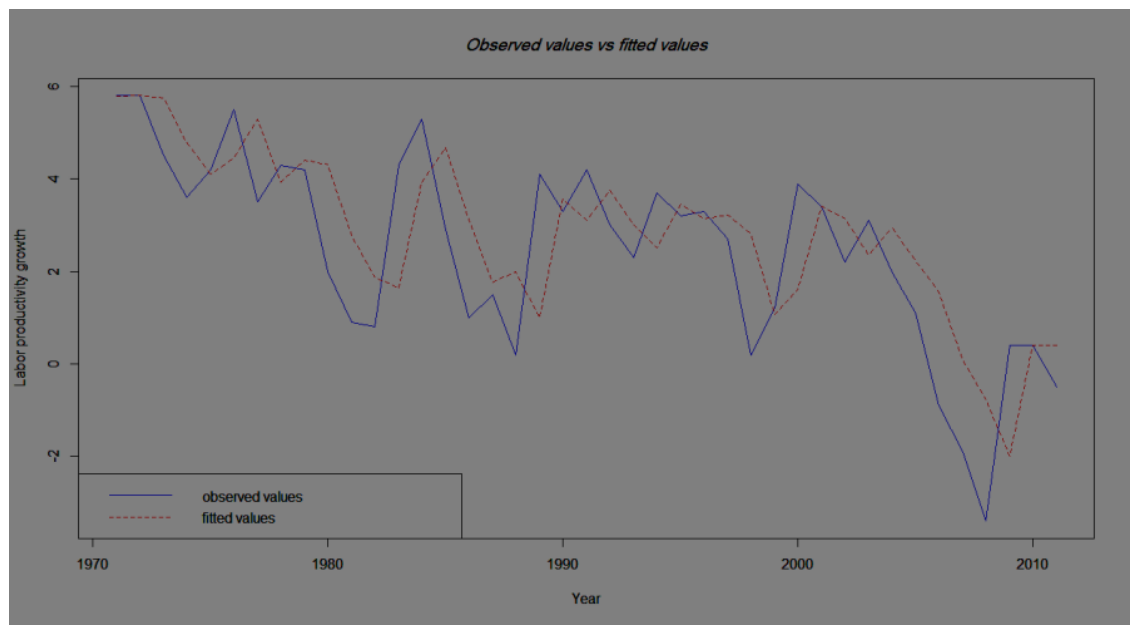




\section{Appendix F}

The forecast for labour productivity growth time series in Norway for the period 2012-2021 using ARIMA $(0,1,0)$ with no constant

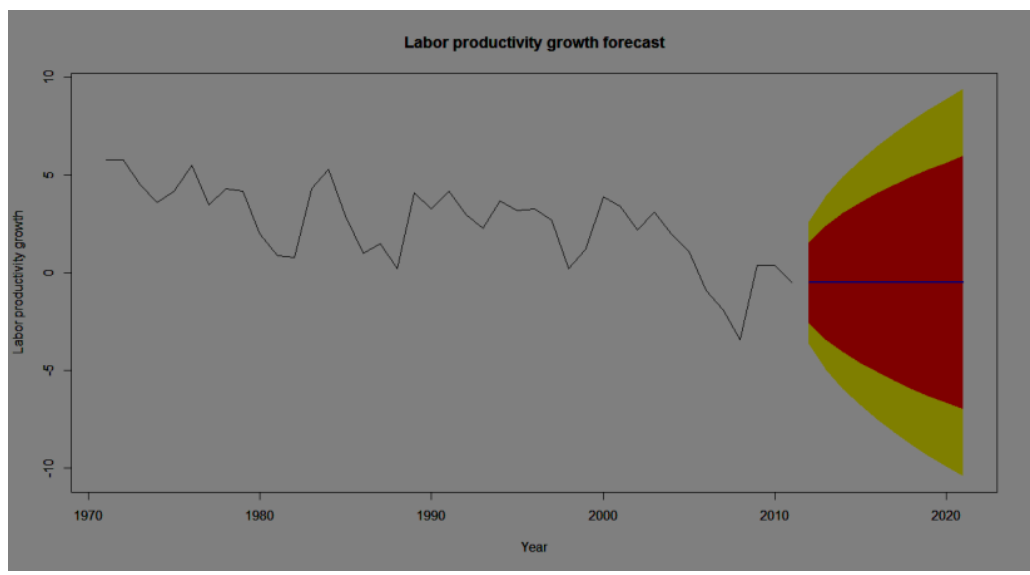

Note: The forecasts for the period 2012-2021 are plotted as a blue line, the $80 \%$ forecast interval as an orange shaded area, and the $95 \%$ forecast interval as a yellow shaded area.

\section{Appendix G}

a) A 20-year forecast (2012-2031) for Norwegian labour productivity growth time series using the selected ARIMA model (ARIMA $(1,1,1)$ with no constant)

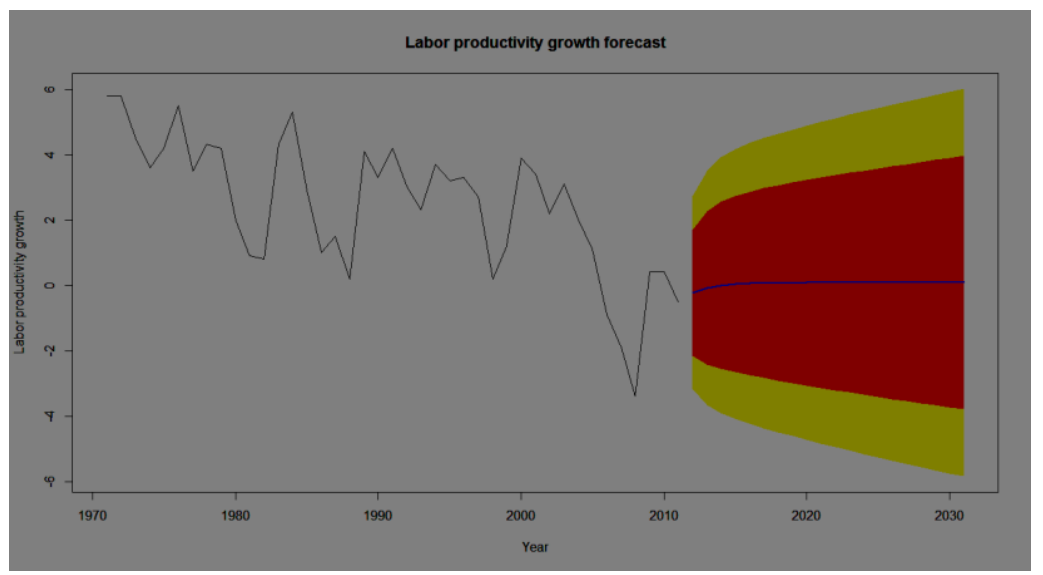

Note: The forecasts for the period 2012-2031 are plotted as a blue line, the $80 \%$ forecast interval as an orange shaded area, and the $95 \%$ forecast interval as a yellow shaded area.

b) A 30-year forecast (2012-2041) for Norwegian labour productivity growth time series using the selected ARIMA model (ARIMA $(1,1,1)$ with no constant) 


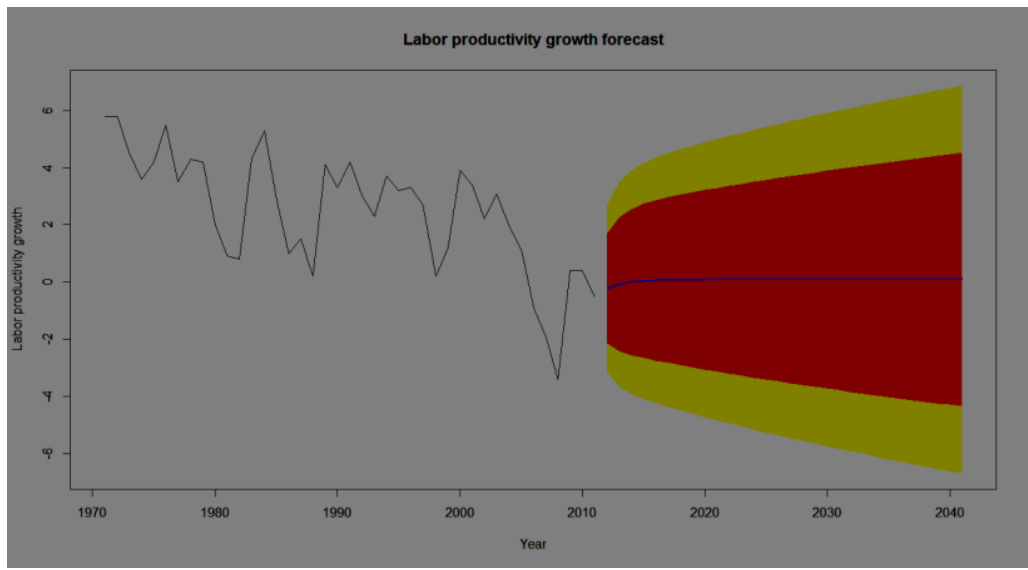

Note: The forecasts for the period 2012-2041 are plotted as a blue line, the $80 \%$ forecast interval as an orange shaded area, and the $95 \%$ forecast interval as a yellow shaded area. 